\title{
A haemodynamic study of pulmonary hypertension in chronic hypersensitivity pneumonitis
}

\author{
Rudolf K.F. Oliveira', Carlos A.C. Pereira', Roberta P. Ramos'1, \\ Eloara V.M. Ferreira', Carolina M.S. Messina', Lilian T. Kuranishi', \\ Andrea Gimenez ${ }^{1}$, Orlando Campos², Célia M.C. Silva² and \\ Jaquelina S. Ota-Arakaki ${ }^{1}$
}

Affiliations: 'Division of Respiratory Diseases, Dept of Medicine, Federal University of São Paulo (UNIFESP), Brazil. ${ }^{2}$ Division of Cardiology, Dept of Medicine, UNIFESP, Brazil.

Correspondence: Carlos A.C. Pereira, Division of Respiratory Diseases, Dept of Medicine, UNIFESP, Rua Botucatu 740, $3^{\circ}$ andar, São Paulo, SP 04023-062, Brazil. E-mail: pereiracQuool.com.br

ABSTRACT Chronic hypersensitivity pneumonitis is a common fibrotic interstitial lung disease. The prevalence of pulmonary hypertension diagnosed by right heart catheterisation and its cardiopulmonary function findings in patients with chronic hypersensitivity pneumonitis are unknown.

Consecutive symptomatic patients with chronic hypersensitivity pneumonitis were prospectively evaluated. All patients were submitted to right heart catheterisation, pulmonary function testing, a 6-min walk test, echocardiography, blood gas determination and N-terminal pro-brain natriuretic peptide analyses. Nonhypoxaemic patients also underwent incremental cardiopulmonary exercise testing.

50 patients underwent right heart catheterisation; 25 (50\%) of these had pulmonary hypertension and 22 (44\%) had a pre-capillary haemodynamic pattern. The patients with pre-capillary pulmonary hypertension had lower forced vital capacity (mean \pm SD $50 \pm 17 \%$ versus $69 \pm 22 \%$ predicted, $\mathrm{p}<0.01$ ), carbon monoxide diffusing capacity $(37 \pm 12 \%$ versus $47 \pm 14 \%$ predicted, $\mathrm{p}<0.01)$, arterial oxygen tension (median (interquartile range) $59.0(47.8-69.3)$ versus $73.0(62.2-78.5) \mathrm{mmHg}, \mathrm{p}<0.01$ ) and saturation after the 6 -min walk test $(78 \pm 8 \%$ versus $86 \pm 7 \%, \mathrm{p}<0.01)$. In pre-capillary pulmonary hypertension, oxygen uptake was also lower at the anaerobic threshold $(41 \pm 11 \%$ versus $50 \pm 8 \%$ predicted, $\mathrm{p}=0.04)$ and at peak exercise $\left(12.8 \pm 1.6\right.$ versus $\left.15.0 \pm 2.5 \mathrm{~mL} \cdot \mathrm{kg}^{-1} \cdot \mathrm{min}^{-1}, \mathrm{p}=0.02\right)$.

Pre-capillary pulmonary hypertension is common in symptomatic chronic hypersensitivity pneumonitis and is related to interstitial lung disease severity. Additionally, pulmonary hypertension is more prevalent in hypoxaemic patients with impaired lung function and exercise capacity.

@ERSpublications

$\mathrm{PH}$ is common in chronic hypersensitivity pneumonitis and is related to interstitial lung disease severity http://ow.ly/uTXXx

For editorial comments see page 287 .

This article has supplementary material available from erj.ersjournals.com

Received: Jan 132014 | Accepted after revision: March 072014 | First published online: April 172014

Support statement: This study was supported by the Pulmonary Vascular Diseases Group Research Fund from UNIFESP, Brazil.

Conflict of interest: None declared.

Copyright @ERS 2014 


\section{Introduction}

Interstitial lung diseases (ILDs) are common causes of pre-capillary pulmonary hypertension (PH) and are classified into group III of the international aetiological classification of $\mathrm{PH}[1,2]$. Pre-capillary $\mathrm{PH}$ is defined by mean pulmonary arterial pressure $(\mathrm{mPAP}) \geqslant 25 \mathrm{mmHg}$ and pulmonary arterial wedge pressure (PAWP) $\leqslant 15 \mathrm{mmHg}$ on right heart catheterisation (RHC) [2]. When present in patients with ILD, precapillary $\mathrm{PH}$ is associated with a significantly poorer prognosis [3-6].

The prevalence of $\mathrm{PH}$ varies widely among the different forms of ILD, depending on the diagnostic algorithm, the $\mathrm{PH}$ definition used and the severity of the underlying parenchymal impairment [7]. Haemodynamic data are mainly available from patients in lung transplantation programmes, in whom a high prevalence of PH is likely because of their ILD severity. In an outpatient setting, echocardiography is frequently used to identify $\mathrm{PH}$. However, this method is commonly inaccurate and can lead to considerable misdiagnosis $[8,9]$, particularly among group III patients $[10,11]$.

Among patients with ILD, hypersensitivity pneumonitis (HP) is a common condition [12]. HP is a pulmonary disease caused by the inhalation of one of various antigens that trigger a diffuse inflammatory response in the small airways and pulmonary parenchyma in susceptible individuals [13]. The causative antigens include bacteria, fungi, protozoa, low-molecular-weight chemical compounds, and animal and insect proteins present in different environments [14]. The spectrum of clinical presentation may vary with the frequency and intensity of antigen exposure and the host immune response [13]. HP can develop into a chronic disease, leading to irreversible lung fibrosis, which characterises chronic HP.

With the exception of two case-series studies [15, 16] and one retrospective study based on echocardiographic diagnosis [17], the literature on $\mathrm{PH}$ in chronic HP is scarce. In particular, there are no published data concerning the prevalence of invasively diagnosed $\mathrm{PH}$ in patients with chronic HP. Therefore, we sought to determine the prevalence of PH at RHC in symptomatic patients with chronic HP, and to compare cardiopulmonary function findings between cases with and without $\mathrm{PH}$.

\section{Material and methods}

Study design and patients

This prospective, cross-sectional study was performed between August 2011 and February 2013 at the ILD Outpatient Clinic of the Federal University of São Paulo, Brazil. We evaluated 1023 consecutive outpatients with ILD who came for a routine consultation during this period. All symptomatic patients from 18-80 years of age with chronic HP were recruited for a standardised $\mathrm{PH}$ assessment. Patients with comorbidities that could lead to $\mathrm{PH}$ were excluded (fig. 1). All patients provided written informed consent, and the study protocol was approved by the Institutional Medical Ethics Committee.

Symptomatic patients were defined as patients with a baseline dyspnoea index $<9$ points at the time of evaluation [18] and stable disease, characterised by the absence of exacerbations and no change in baseline therapy during the 30 days before study enrolment.

Patients with chronic HP were defined as patients with relevant exposure preceding respiratory symptoms [19] and fibrotic disease visible on high-resolution computed tomography (HRCT) scans of the lungs, without another identifiable cause of ILD, in addition to at least one of the following findings. 1) Improvement of symptoms upon the withdrawal of exposure or clinical/functional deterioration upon re-exposure [20]. 2) At least two of the following HRCT-consistent HP findings: bilateral ground-glass opacity, poorly defined centrilobular nodules and mosaic patterns [21]. 3) A classic histological triad characterised by chronic interstitial pneumonia with peribronchiolar accentuation, bronchiolitis and non-necrotising granulomas or giant cells [22]. 4) Other consistent histological findings, including bronchiolocentric interstitial pneumonia, nonspecific interstitial pneumonia (NSIP) or usual interstitial pneumonia (UIP)-like findings [22].

\section{Measurements}

All patients were submitted to RHC, pulmonary function testing (PFT), a 6-min walk test (6MWT), echocardiography, blood gas analysis and serum $\mathrm{N}$-terminal pro-brain natriuretic peptide level determination. Nonhypoxaemic patients (arterial oxygen saturation $\left(\mathrm{SaO}_{2}\right)>90 \%$ at rest) without musculoskeletal limitations were also submitted to incremental cardiopulmonary exercise testing (CPET).

RHC was performed using a Swan-Ganz catheter inserted percutaneously via the internal jugular vein. Cardiac output was measured using the thermodilution technique. Pre-capillary PH was defined as mPAP $\geqslant 25 \mathrm{mmHg}$ and PAWP $\leqslant 15 \mathrm{mmHg}$ at rest [2]. 


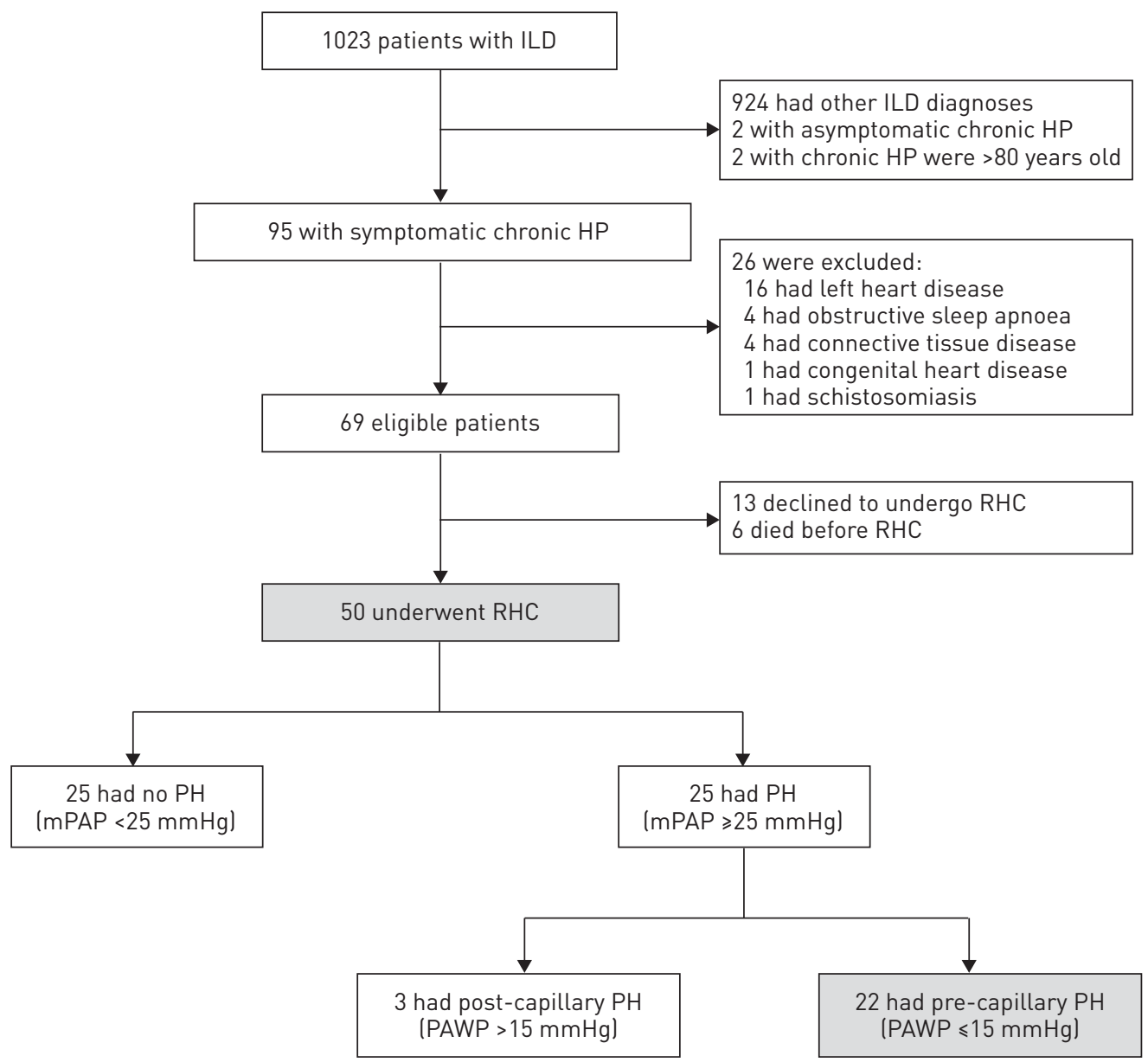

FIGURE 1 Study flow diagram. ILD: interstitial lung disease; HP: hypersensitivity pneumonitis; RHC: right heart catheterisation; PH: pulmonary hypertension; mPAP: mean pulmonary arterial pressure; PAWP: pulmonary arterial wedge pressure.

Echocardiography was performed according to the American Society of Echocardiography guidelines [23] using the modified Bernoulli equation and the right atrial pressure to estimate the systolic pulmonary arterial pressure (sPAP).

Patients on continuous home oxygen therapy underwent RHC, the 6MWT and echocardiography under their usual oxygen supplementation. RHC was performed 7-21 days after study enrolment and dyspnoea quantification. All examinations were performed 1-14 days after RHC under stable clinical conditions.

Detailed methods are provided in the online supplementary material.

\section{Statistical analysis}

Data are presented as mean \pm SD or median (interquartile range), unless otherwise stated. The distribution of continuous variables was evaluated using Kolmogorov-Smirnov and Shapiro-Wilk tests. Comparisons between patients with and without $\mathrm{PH}$ were made using a t-test or Mann-Whitney test, where appropriate. Categorical variables were compared using Chi-squared and Fisher's exact tests. Between-group comparisons across different mPAP ranges were performed using ANOVA with Tukey's post hoc analysis. Correlations between variables were calculated using Pearson's correlation coefficient. Receiver operating characteristic (ROC) curves for forced vital capacity (FVC), diffusing capacity of the lung for carbon monoxide (DLCO) and arterial oxygen tension $\left(\mathrm{PaO}_{2}\right)$ at rest were derived while accounting for the presence or absence of $\mathrm{PH}$. The thresholds for each ROC curve were obtained from the points with the greatest sum of sensitivity and specificity. Variables that were statistically significant in the univariate analysis $(\mathrm{p}<0.05)$ were transformed into categorical variables based on the ROC analysis and included in a logistic regression model to estimate the probability of $\mathrm{PH}$. To avoid multicollinearity, only one of the highly correlated 
variables $(r \geqslant 0.6)$ was included in the model. $\mathrm{p}<0.05$ was considered significant. The statistical analyses were performed using SPSS software, version 19 (IBM Company, Armonk, NY, USA).

\section{Results}

Prevalence of $\mathrm{PH}$ and overall cohort description

A total of 95 consecutive symptomatic patients with chronic HP were evaluated. 26 were excluded because of significant comorbidities, six died before RHC and 13 declined to participate. 50 patients underwent RHC; 25 (50\%) had PH and 22 (44\%) demonstrated a pre-capillary pattern (fig. 1). Most patients had mild $\mathrm{PH}$, with $\mathrm{mPAP} \leqslant 35 \mathrm{mmHg}$ (fig. 2).

The main exposures were to moulds $(n=24)$, birds $(n=8)$ or both $(n=17)$, and one patient had hot-tub lung. Lung biopsies were performed in $33(66 \%)$ patients. Of these, 12 showed the classic histological triad, 16 showed bronchiolocentric interstitial pneumonia, three showed NSIP and two showed UIP-like findings. The diagnosis of 17 (34\%) patients was based on clinical and radiological findings. In total, 32 patients were being treated with corticosteroids, with a median dose of $20 \mathrm{mg}$ per day. The median disease duration from diagnosis was 23 months, with an interquartile range of 3-71 months. All patients were nonsmokers or exsmokers and no patient had emphysema on HRCT. The patients' baseline characteristics are shown in table 1.

\section{Comparisons of patients with and without pre-capillary PH at RHC}

Patients with pre-capillary $\mathrm{PH}$ had significantly lower FVC, forced expiratory volume in the $1 \mathrm{~s}$ (FEV1), DLCO, $\mathrm{PaO}_{2}$ and oxygen saturation values at the end of the 6MWT compared with patients without $\mathrm{PH}$ (table 1). In contrast, the absence of anti-inflammatory therapy, the histological pattern and the disease duration from diagnosis were not associated with $\mathrm{PH}$ (data not shown). Haemodynamic, pulmonary function and echocardiographic characteristics across different mPAP ranges, as assessed by RHC, are shown in table 2.

FVC and FEV1 values could not be obtained in two patients. DLCO values could not be obtained in nine patients; in seven of these patients, this was because their FVC was $<1 \mathrm{~L}$. Moreover, sPAP could not be estimated for 17 patients (eight from the pre-capillary PH group) because of a lack of a detectable tricuspid regurgitant jet.

There were significant inverse correlations between mPAP and $\mathrm{PaO}_{2}(\mathrm{r}=0.57, \mathrm{p}<0.01), \mathrm{FVC}(\mathrm{r}=0.44$, $\mathrm{p}<0.01)$ and DLCO $(\mathrm{r}=0.37, \mathrm{p}=0.02)$. ROC analysis (fig. 3 ) demonstrated an area under the curve of 0.78 for $\mathrm{PaO}_{2}(95 \%$ CI $0.63-0.92, \mathrm{p}<0.01), 0.73$ for FVC (95\% CI 0.57-0.89, $\left.\mathrm{p}=0.01\right)$ and 0.69 for DLCO (95\% CI $0.52-0.86, \mathrm{p}=0.05)$. Based on the ROC analysis, an $\mathrm{FVC}$ of $60 \%, \mathrm{PaO}_{2}$ of $70 \mathrm{mmHg}$ and $\mathrm{DLCO}$ of $50 \%$ were the optimal cut-offs in the presence of pre-capillary $\mathrm{PH}$. In the multivariate analysis, these FVC (hazard ratio (HR) 4.18, 95\% CI 1.10-17.54; $\mathrm{p}=0.04$ ) and $\mathrm{PaO}_{2}(\mathrm{HR} 7.04,95 \% \mathrm{CI} 1.66-30.30 ; \mathrm{p}<0.01)$ cut-offs were shown to be independent predictors of pre-capillary $\mathrm{PH}$.

\section{Cardiopulmonary exercise testing}

In total, 33 nonhypoxaemic patients $\left(\mathrm{SaO}_{2}>90 \%\right)$ were enrolled for CPET. Four patients could not undergo CPET because of musculoskeletal limitations, so 29 patients were evaluated. These patients had less severe ILD than did the patients who did not undergo CPET, as indicated by higher FVC (mean \pm SD $65 \pm 21 \%$

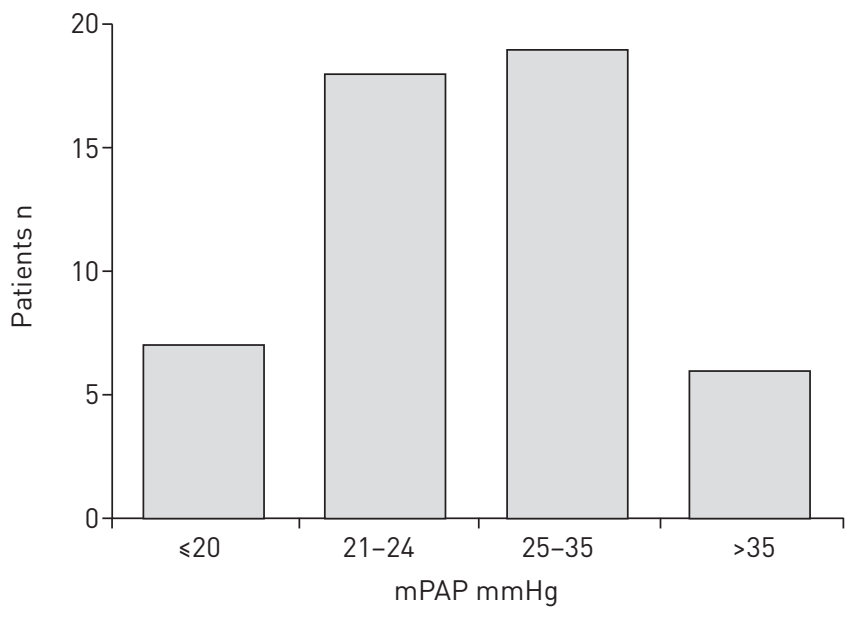

FIGURE 2 Patients' frequency distribution across mean pulmonary arterial pressure (mPAP) ranges. Patients with a post-capillary haemodynamic pattern had an mPAP of $25-35 \mathrm{mmHg}(\mathrm{n}=2)$ or $>35 \mathrm{mmHg}(\mathrm{n}=1)$. 
TABLE 1 Baseline characteristics of patients with symptomatic chronic hypersensitivity pneumonitis

\begin{tabular}{|c|c|c|c|c|}
\hline & Total & Non-PH & Pre-capillary PH & p-value ${ }^{\#}$ \\
\hline Patients & 50 & 25 & 22 & \\
\hline Age years & $61 \pm 11$ & $61 \pm 12$ & $60 \pm 11$ & 0.80 \\
\hline Body mass index $\mathrm{kg} \cdot \mathrm{m}^{-2}$ & $28 \pm 5$ & $28 \pm 5$ & $28 \pm 6$ & 0.59 \\
\hline Baseline dyspnoea index & $6 \pm 2$ & $6 \pm 2$ & $5 \pm 2$ & 0.07 \\
\hline NYHA functional class II/III/IV & $18 / 27 / 2$ & $10 / 15 / 0$ & $8 / \overline{12 / 2}$ & 0.31 \\
\hline FEV1 \% predicted & $65 \pm 24$ & $75 \pm 23$ & $54 \pm 17$ & $<0.01$ \\
\hline DLCo \% predicted & $44 \pm 15$ & $47 \pm 14$ & $37 \pm 12$ & 0.03 \\
\hline FVC/DLco \% predicted & $1.5(1.4-1.7)$ & $1.5(1.3-1.7)$ & $1.6(1.4-1.8)$ & 0.68 \\
\hline \multicolumn{5}{|l|}{ Blood gas analysis } \\
\hline $\mathrm{PaO}_{2}$ at rest $\mathrm{mmHg}$ & $68.5(54.5-75.0)$ & $73.0(62.2-78.5)$ & $59.0(47.8-69.3)$ & $<0.01$ \\
\hline $\mathrm{PaCO}_{2}$ at rest $\mathrm{mmHg}$ & $37.9 \pm 4.7$ & $37.5 \pm 3.8$ & $38.1 \pm 5.4$ & 0.68 \\
\hline TRV $\mathrm{m} \cdot \mathrm{s}^{-1}$ & $2.8 \pm 0.6$ & $2.6 \pm 0.3$ & $3.1 \pm 0.8$ & 0.08 \\
\hline sPAP mmHg & $35(30-40)$ & $34(30-36)$ & $38(29-49)$ & 0.31 \\
\hline NT-proBNP pg $\cdot \mathrm{mL}^{-1}$ & $78.7(44.9-143.1)$ & $78.7(49.7-128.4)$ & $68.8(34.8-145.8)$ & 0.71 \\
\hline \multicolumn{5}{|l|}{ Right heart catheterisation } \\
\hline RAP mmHg & $8 \pm 4$ & $7 \pm 3$ & $7 \pm 4$ & 0.72 \\
\hline $\mathrm{mPAP} \mathrm{mmHg}$ & $25(21-30)$ & $21(20-23)$ & $30(27-35)$ & $<0.01$ \\
\hline PAWP mmHg & $10 \pm 4$ & $10 \pm 3$ & $10 \pm 4$ & 0.74 \\
\hline TPG mmHg & $15(11-19)$ & $11(10-14)$ & $19(1 \overline{7}-25)$ & $<0.01$ \\
\hline PVR Wood units & $3.2(2.3-3.8)$ & $2.3(1.9-2.8)$ & $4.0(3.5-4.9)$ & $<0.01$ \\
\hline Cardiac index $\mathrm{L} \cdot \mathrm{min}^{-1} \cdot \mathrm{m}^{-2}$ & $2.8(2.4-3.0)$ & $2.8(2.4-3.2)$ & $2.7(2.4-2.9)$ & 0.59 \\
\hline
\end{tabular}

Data are presented as $n, \mathrm{n}(\%)$, mean \pm SD or median (interquartile range), unless otherwise stated. PH: pulmonary hypertension; NYHA: New York Heart Association; FVC: forced vital capacity; FEV1: forced expiratory volume in $1 \mathrm{~s}$; DLCo: diffusing capacity of the lung for carbon monoxide; PaO ${ }_{2}$ : arterial oxygen tension; $\mathrm{PaCO}_{2}$ : arterial carbon dioxide tension; $\mathrm{SpO}_{2}$ : arterial oxygen saturation measured by pulse oximetry; TRV: tricuspid regurgitant jet velocity; SPAP: systolic pulmonary arterial pressure; NT-proBNP: N-terminal pro-brain natriuretic peptide; RAP: right atrial pressure; mPAP: mean pulmonary arterial pressure; PAWP: pulmonary arterial wedge pressure; TPG: transpulmonary gradient; PVR: pulmonary vascular resistance. " : comparing pre-capillary PH patients with non-PH patients. ": FVC and FEV1 values could not be obtained in two patients lone from each group); DLCO values could not be obtained in nine patients (six from the pre-capillary PH group). ${ }^{+}$: 17 patients had no detectable tricuspid regurgitant jet (eight from the pre-capillary PH group).

versus $50 \pm 20 \%$ predicted, $\mathrm{p}=0.03)$ and $\mathrm{PaO}_{2}(72.8 \pm 7.5$ versus $51.9 \pm 10.6 \mathrm{mmHg}, \mathrm{p}<0.01)$ values. None of the patients with mPAP $>35 \mathrm{mmHg}$ underwent CPET because of low $\mathrm{SaO}_{2}$ at rest. Oxygen uptake $\left(V^{\prime} \mathrm{O}_{2}\right)$ at peak exercise and at the anaerobic threshold (AT) was significantly lower in the PH group (table 3 ). However, no significant differences were found for the other CPET parameters. Among the 29 patients who underwent CPET, the patients with pre-capillary $\mathrm{PH}(\mathrm{n}=10)$ had lower values than did the patients without $\mathrm{PH}(\mathrm{n}=19)$ for FVC $(55 \pm 10 \%$ versus $70 \pm 23 \%$ predicted, $\mathrm{p}=0.02)$, DLCO $(37 \pm 10 \%$ versus $49 \pm 15 \%$ predicted, $\mathrm{p}=0.03)$ and $\mathrm{PaO}_{2}(68.5 \pm 5.8$ versus $75.1 \pm 7.5 \mathrm{mmHg}, \mathrm{p}=0.02)$.

\section{Echocardiography}

Nearly all patients for whom echocardiography indicated sPAP $\geqslant 40 \mathrm{mmHg}$ had pre-capillary $\mathrm{PH}$, as confirmed by RHC (fig. S1). However, patients with pre-capillary PH had the greatest differences between the sPAP values estimated by echocardiography and values measured by RHC (fig. 4). In this patient subgroup, echocardiography underestimated the value provided by invasive measurement by up to $23 \mathrm{mmHg}$ and overestimated by up to $38 \mathrm{mmHg}$. In the group without $\mathrm{PH}$, most patients presented a difference of $\pm 10 \mathrm{mmHg}$ between the two measurements.

\section{PH risk assessment score}

We found that at least two of the following findings were present in $76 \%$ of patients with chronic $\mathrm{HP}$ and pre-capillary $\mathrm{PH}$ : FVC $\leqslant 60 \%$ predicted, $\mathrm{PaO}_{2} \leqslant 70 \mathrm{mmHg}$ and $\mathrm{sPAP} \geqslant 40 \mathrm{mmHg}$ on echocardiography. There were no cases of $\mathrm{PH}$ among patients with none of these findings. Based on this observation, we 
TABLE 2 Haemodynamic, pulmonary functional and echocardiographic characteristics across different mean pulmonary arterial pressure (mPAP) ranges

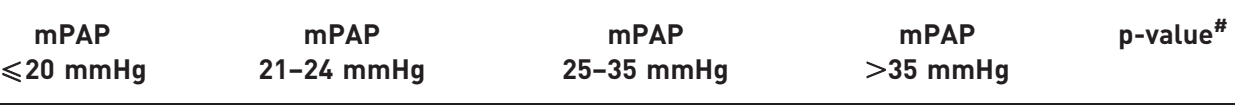

\begin{tabular}{|c|c|c|c|c|c|}
\hline Patients n & 7 & 18 & 17 & 5 & \\
\hline PVR Wood units & $2.2 \pm 0.7$ & $2.5 \pm 0.5$ & $4.2 \pm 1.1^{*, \S}$ & $6.0 \pm 1.4^{*, \S, f}$ & $<0.01$ \\
\hline Cardiac index $\mathrm{L} \cdot \mathrm{min}^{-1} \cdot \mathrm{m}^{-2}$ & $2.6 \pm 0.5$ & $2.9 \pm 0.5$ & $2 . \overline{7} \pm 0.3$ & $2.7 \pm 0.2$ & 0.51 \\
\hline FVCा \% predicted & $65 \pm 16$ & $70 \pm 24$ & $52 \pm 17^{\S}$ & $38 \pm 14^{\S}$ & 0.01 \\
\hline $\mathrm{PaO}_{2}$ at rest $\mathrm{mmHg}$ & $75.9 \pm 8.3$ & $68.8 \pm 11.9$ & $61.6 \pm 11.2^{*}$ & $45.4 \pm 9.4^{*, \S, f}$ & $<0.01$ \\
\hline 6MWT final $\mathrm{SpO}_{2} \%$ & $87 \pm 6$ & $85 \pm 8$ & $81 \pm 7$ & $69 \pm 5^{*, \S, f}$ & $<0.01$ \\
\hline $\mathrm{TRV}^{+} \mathrm{m} \cdot \mathrm{s}^{-1}$ & $2.5 \pm 0.3$ & $2.7 \pm 0.3$ & $2.7 \pm 0.5$ & $3.8 \pm 0.8^{*, \S, f}$ & $<0.01$ \\
\hline sPAP on echocardiography ${ }^{+} \mathrm{mmHg}$ & $33 \pm 3$ & $33 \pm 6$ & $34 \pm 11$ & $38 \pm 16^{*, \S, f}$ & $<0.01$ \\
\hline
\end{tabular}

Data are presented as mean \pm SD unless otherwise stated. PVR: pulmonary vascular resistance; FVC: forced vital capacity; PaO ${ }_{2}$ : arterial oxygen tension; 6MWT: 6-min walk test; $\mathrm{SpO}_{2}$ : arterial oxygen saturation measured by pulse oximetry; TRV: tricuspid regurgitant jet velocity; sPAP: systolic pulmonary arterial pressure. ${ }^{*}$ : intergroup comparison by ANOVA; ${ }^{\text {I: }}$ could not be obtained in two patients lone had an mPAP of $21-24$ mmHg and one had mPAP $>35 \mathrm{mmHg}$ ); ${ }^{+}: 17$ patients had no detectable tricuspid regurgitant jet (three had mPAP $\leqslant 20 \mathrm{mmHg}$, six had an mPAP of

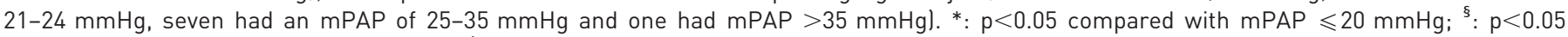
compared with an mPAP of $21-24 \mathrm{mmHg}_{;}{ }^{f}: \mathrm{p}<0.05$ compared with an mPAP of $25-35 \mathrm{mmHg}$.

developed a risk assessment score for PH. One point was given for each of the following findings: sPAP $\geqslant 40 \mathrm{mmHg}$ on echocardiography, $\mathrm{FVC} \leqslant 60 \%$ predicted and $\mathrm{PaO}_{2} \leqslant 70 \mathrm{mmHg}$. The absence of a detectable tricuspid regurgitant jet was assigned zero points. The distribution of patients with and without $\mathrm{PH}$ according to risk assessment scores is shown in table 4.

\section{Discussion}

In this study, we found that pre-capillary $\mathrm{PH}$ is common in symptomatic patients with chronic HP, with a prevalence of $44 \%$, as assessed by RHC. Additionally, we found that pre-capillary PH is related to ILD severity, as indicated by its greater frequency in hypoxaemic patients with reduced lung function and exercise capacity.

Data on PH in chronic HP are scarce. Our study is the first to systematically evaluate PH using RHC in a large cohort of patients with chronic HP. Two case-series studies have also been reported [15, 16]. LuPIHerrera et al. [15] described 10 patients with invasively diagnosed HP whose mPAP was $22 \pm 2 \mathrm{mmHg}$. All of these patients were hypoxaemic. However, the study was conducted $2240 \mathrm{~m}$ above sea level, which raises doubts about whether the PH and hypoxaemia were produced by ILD or high altitude [15]. In the second study, COSTABEL et al. [16] reported nine cases of invasively studied HP, seven of which had mild PH (mPAP $20 \pm 7 \mathrm{mmHg})$.

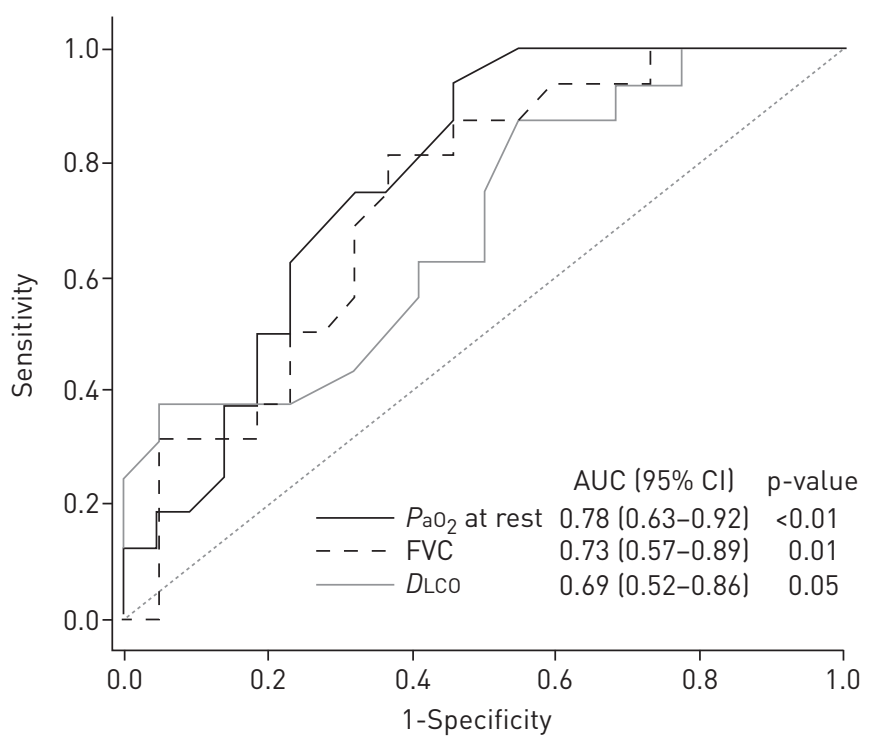

FIGURE 3 Receiver operating characteristic curves for arterial oxygen ten$\operatorname{sion}\left(\mathrm{PaO}_{2}\right)$ at rest, forced vital capacity (FVC) and diffusing capacity of the lung for carbon monoxide (DLCO) for the diagnosis of pre-capillary pulmonary hypertension. AUC: area under the curve. 
Non-PH

Patients n

\section{Peak WR W}

Metabolic responses

Peak $\mathrm{V}^{\prime} \mathrm{O}_{2} \%$ predicted

Peak $V^{\prime} \mathrm{O}_{2} \mathrm{~mL} \cdot \mathrm{kg}^{-1} \cdot \mathrm{min}^{-1}$

$V^{\prime} \mathrm{O}_{2}$ at $\mathrm{AT}^{\top} \% \mathrm{~V}^{\prime} \mathrm{O}_{2}$ max predicted

$\Delta V^{\prime} \mathrm{O}_{2} / \Delta \mathrm{WR} \mathrm{mL} \cdot \mathrm{min}^{-1} \cdot \mathrm{W}^{-1}$

Cardiovascular responses

Peak heart rate beats $\cdot \mathrm{min}^{-1}$

Peak heart rate $\%$ predicted

$\Delta$ heart rate $/ \Delta V^{\prime} \mathrm{O}_{2}$ beats $\cdot \mathrm{L}^{-1}$

Peak $V^{\prime} \mathrm{O}_{2} /$ heart rate $\%$ predicted

Peak SBP $\mathrm{mmHg}$

Ventilatory responses

$V^{\prime} \mathrm{E} / \mathrm{MVV}$

$\Delta V^{\prime} E / \Delta V^{\prime} \mathrm{CO}_{2}$

$V^{\prime} E / V^{\prime} \mathrm{CO}_{2}$ at $A T^{\circ}$

Peak $\mathrm{PETCO}_{2} \mathrm{mmHg}$

$\mathrm{PETCO}_{2}$ at $\mathrm{AT}^{*} \mathrm{mmHg}$

Peak $\mathrm{SpO}_{2} \%$

Subjective responses

Peak dyspnoea Borg score

Peak leg effort Borg score

Pre-capillary PH

p-value

$49(38-55)$

$80 \pm 13$

$15.0 \pm 2.5$

$50 \pm 8$

$8.8 \pm 1.6$

$124 \pm 22$

$77 \pm 15$

$69 \pm 27$

97 (85-117)

$170(160-170)$

$0.61(0.51-0.92)$

$40 \pm 5$

$37 \pm 7$

$35 \pm 4$

$37 \pm 4$

$93(86-95)$

$5 \pm 2$
$45(30-64)$

$68 \pm 20$

$12.8 \pm 1.6$

0.06

$41 \pm 11$

$9.9 \pm 2.9$

0.02

0.04

0.24

$121 \pm 14$

0.72

$76 \pm 5$

0.75

$62 \pm 24$

0.27

$99(62-110)$

0.51

155 (150-163)

0.05

$0.66(0.60-0.86)$

0.65

$42 \pm 6$

$38 \pm 7$

$36 \pm 5$

$38 \pm 5$

0.78

0.67

0.61

0.79

$87(84-90)$

0.06

$6 \pm 2$
$6 \pm 2$

$5 \pm 3$
0.51

0.31

Data are presented as median (interquartile range) or mean $\pm \mathrm{SD}$, unless otherwise stated. $\mathrm{PH}$ : pulmonary hypertension; WR: work rate; $V^{\prime} \mathrm{O}_{2}$ : oxygen uptake; AT: anaerobic threshold; $\Delta$ : change in; SBP; systolic blood pressure; $V^{\prime} E$ : minute ventilation; MVV: maximal voluntary ventilation; $\mathrm{V}^{\prime} \mathrm{CO}_{2}$ : carbon dioxide production; $\mathrm{PETCO}_{2}$ : end-tidal carbon dioxide tension; $\mathrm{SpO}_{2}$ : arterial oxygen saturation measured by pulse oximetry. ${ }^{\#}: \mathrm{n}=29$;

$\because$ : we were not able to determine the AT in eight patients (three from the pre-capillary PH group).

One recent retrospective study based on echocardiographic diagnosis (sPAP $\geqslant 50 \mathrm{mmHg}$ ) described 73 patients with chronic HP with a 19\% prevalence of $\mathrm{PH}$ [17], which is well below our finding of $44 \%$. The noninvasive diagnostic approach and retrospective design of the prior study may explain the lower prevalence of $\mathrm{PH}$ compared with our results. Despite this difference in the reported prevalence of $\mathrm{PH}$, Koschel et al. [17] found that $\mathrm{PaO}_{2}$ and FVC correlated with $\mathrm{PH}$, although only $\mathrm{PaO}_{2}$ was significantly decreased among patients with $\mathrm{SPAP} \geqslant 50 \mathrm{mmHg}$.

Echocardiography is known to have certain limitations in $\mathrm{PH}$ diagnosis [8, 9], especially in parenchymal lung diseases $[10,11]$. If our study were based on only echocardiographic findings, we would have missed

FIGURE 4 Patients' distribution according to the difference between the systolic pulmonary arterial pressure (sPAP) estimated by echocardiography and the sPAP measured by right heart catheterisation (RHC) in relation to the mean pulmonary artery pressure (mPAP). 17 patients had no detectable tricuspid regurgitant jet.

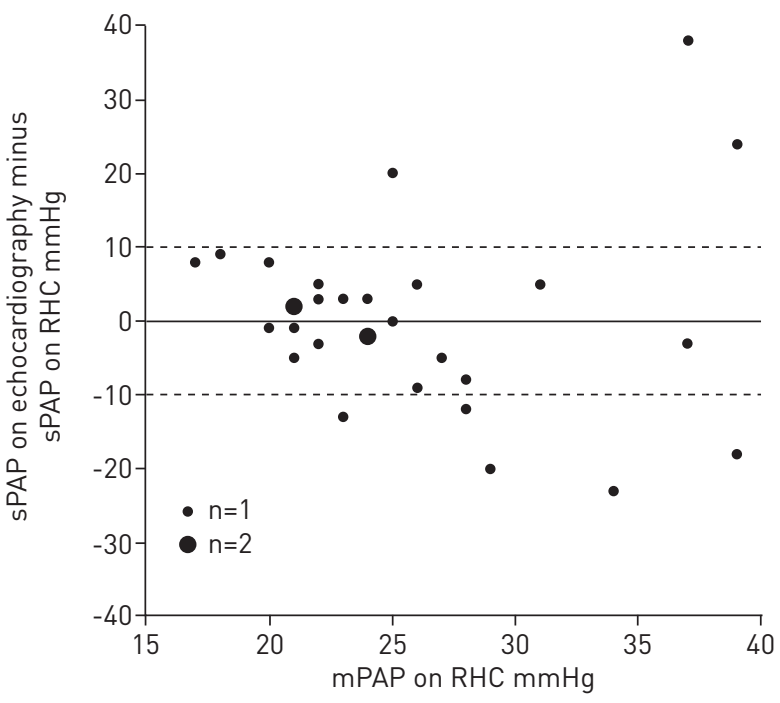


TABLE 4 Distribution of symptomatic patients with chronic hypersensitivity pneumonitis with and without pulmonary hypertension according to the risk assessment score for pulmonary hypertension

\section{Points ${ }^{\#}$}

mPAP at right heart catheterisation

Total

\begin{tabular}{|c|c|c|c|}
\hline & $<25 \mathrm{mmHg}$ & $\geqslant 25 \mathrm{mmHg}$ & \\
\hline 0 & 11 & 0 & 11 \\
\hline 1 & 9 & 8 & 17 \\
\hline$\geqslant 2$ & 4 & 13 & 17 \\
\hline Total & 24 & 21 & 45 \\
\hline
\end{tabular}

Data are presented as $\mathrm{n}$. Chi-squared $17.00, \mathrm{p}<0.01$ by Fisher's exact test. mPAP: mean pulmonary arterial pressure. " : one point was given for each of the following findings: systolic pulmonary arterial pressure $\geqslant 40 \mathrm{mmHg}$ on echocardiography, forced vital capacity $\leqslant 60 \%$ predicted and arterial oxygen tension $\leqslant 70 \mathrm{mmHg}$ at rest. The absence of a detectable tricuspid regurgitant jet by echocardiography was assigned zero points. Forced vital capacity values could not be obtained in two patients.

17 (34\%) patients because of the absence of tricuspid regurgitation and would have failed to diagnose three cases of post-capillary PH. Additionally, if the selection criteria for RHC were based on a tricuspid regurgitant jet velocity $(\mathrm{TRV}) \geqslant 2.5 \mathrm{~m} \cdot \mathrm{s}^{-1}, 26$ patients would have been deprived of invasive haemodynamic evaluation, including 11 patients with pre-capillary $\mathrm{PH}$ and two patients with post-capillary PH. Therefore, reliance solely on a PH suspicion threshold $\geqslant 2.5 \mathrm{~m} \cdot \mathrm{s}^{-1}$ for TRV on echocardiography would have missed $50 \%$ of the patients with pre-capillary $\mathrm{PH}$.

Among patients with ILD, PH has been more frequently studied in idiopathic pulmonary fibrosis (IPF) and sarcoidosis [24]. The prevalence of PH among patients with IPF ranges from $8 \%$ to $84 \%[3,25,26]$, with higher prevalence among patients in lung transplant programmes [26]. However, $\mathrm{PH}$ is also common among nonhypoxaemic patients with mild-to-moderate functional impairment, with a nearly $15 \%$ prevalence as assessed by RHC [5]. This finding suggests that PH may be related to remodelling of the pulmonary vascular bed, independent of the severity of lung fibrosis or hypoxaemia [27]. In sarcoidosis, the prevalence of $\mathrm{PH}$ ranges from $6 \%$ to $74 \%[4,28,29]$ and $\mathrm{PH}$ can occur even in the absence of ILD [30]. However, $\mathrm{PH}$ is more frequent in patients with advanced parenchymal fibrosis [31], in which the predominant mechanisms of $\mathrm{PH}$ are hypoxaemia, parenchymal destruction and distortion of the lung microcirculation [32].

In contrast to IPF and similar to advanced stages of sarcoidosis, our findings suggest that in chronic $\mathrm{HP}, \mathrm{PH}$ severity is proportional to ILD severity. $\mathrm{PH}$ was more frequent among patients with lower lung function and hypoxaemia. The latter is a well-known cause of $\mathrm{PH}$ induction via pulmonary vasoconstriction and remodelling.

Beyond disease severity, the inflammatory response related to chronic HP [14] could represent another possible contributor to $\mathrm{PH}$ development. Inflammatory mechanisms play important roles in the pathogenesis of pulmonary arterial hypertension [33] and are, for example, assumed to contribute to altered pulmonary circulation in chronic obstructive pulmonary disease [34]. Recent studies suggest that allergen-induced lung inflammation is accompanied by significant pulmonary vascular hyperresponsiveness and pulmonary arterial muscularisation, which may contribute to vascular remodelling and $\mathrm{PH}$ development $[35,36]$. However, in our study, anti-inflammatory therapy was not associated with an absence of $\mathrm{PH}$.

PH has a significant impact on exercise capacity in patients with ILD [37]. CPET has already been shown to be effective in identifying $\mathrm{PH}$ in patients with IPF because of the remarkable ventilatory inefficiency present when these patients develop PH [38]. In our study, a dynamic exercise evaluation using CPET showed reduced exercise capacity in pre-capillary $\mathrm{PH}$ patients, as demonstrated by lower $V \mathrm{O}_{2}$ at peak exercise and at the AT than in patients without PH. We did not find any other ventilatory or metabolic PH predictors. Possible explanations for this finding include that few patients were enrolled for CPET $(n=29)$ and that CPET was performed only in nonhypoxaemic patients, i.e. those with less severe ILD. Another possible explanation for our CPET findings is the likely different pathophysiologies of $\mathrm{PH}$ in IPF and $\mathrm{PH}$ in chronic HP. Patients with IPF who develop PH may have pulmonary vasculopathy independent of ILD severity, which could justify the presence of ventilatory inefficiency on CPET. 
Although the patients who underwent CPET had less severe pulmonary function impairment, the patients with pre-capillary $\mathrm{PH}(\mathrm{n}=10)$ had lower FVC and $\mathrm{PaO}_{2}$ values than did the patients without $\mathrm{PH}$ who also underwent CPET $(n=19)$, which reinforces the observation that pre-capillary PH is related to the severity of chronic HP.

To help to identify patients with chronic HP and pre-capillary $\mathrm{PH}$, we developed a risk assessment score for $\mathrm{PH}$ using variables routinely obtained in outpatient settings (FVC, $\mathrm{PaO}_{2}$ and sPAP on echocardiography). We found that scores $\geqslant 2$ points were suggestive of $\mathrm{PH}$ and a score of zero indicated the absence of $\mathrm{PH}$. This risk assessment score could help physicians to stratify patients to identify those who need invasive investigation by RHC. However, this score was derived from a small population, so further validation is needed in a larger population with chronic HP before clinical use.

The presence of PH represents a known marker for a poor prognosis in ILD [1]. In chronic HP, the prognosis is associated with the presence of fibrosis (especially a UIP-like pattern) but is not correlated with FVC $[39,40]$. Another predictor of survival is oxygen desaturation during exercise [12]. Furthermore, $\mathrm{PH}$ seems to represent an adverse prognostic marker in patients with chronic HP [17]. Although the present study was not designed to evaluate survival, we intend to follow this patient cohort over an extended period to evaluate the utility of the presence of $\mathrm{PH}$ as a predictor of survival.

This study had certain limitations. It was a single-centre study, with potential bias in the patient selection process. Another potential limitation is that we evaluated only patients with HRCT-confirmed fibrosis. This population could have more severe ILD, which could affect the prevalence of PH. However, patients with chronic HP and fibrosis are of greater interest regarding $\mathrm{PH}$ development compared with acute/subacute HP cases that have potentially reversible disease. Additionally, we did not quantify fibrosis using HRCT. However, the PFT parameters are assumed to be physiological correlates of the extent of lung fibrosis and, therefore, could be sufficient to determine ILD severity.

Another limitation of our study is the number of patients in whom DLCO values could not be obtained $(n=9)$, seven because their FVC was $<1 \mathrm{~L}$. This may have influenced the correlation between DLCO and mPAP, as HP was more frequent in patients with reduced FVC.

We did not evaluate serum precipitins because this test is not available in our country and we did not perform bronchoalveolar lavage in many patients. However, there are no standardised diagnostic criteria for chronic HP that require these two examinations. HP diagnosis depends on a high level of clinical suspicion, recognition of relevant antigen exposure preceding the onset of respiratory symptoms (which represents a key component of HP diagnosis), and the association of clinical, radiological, laboratory and pathological findings $[14,19]$, without another identifiable cause of ILD.

In conclusion, our study demonstrated that pre-capillary $\mathrm{PH}$ in symptomatic patients with chronic $\mathrm{HP}$ is common. The presence of $\mathrm{PH}$ is related to ILD severity, as indicated by the observation that $\mathrm{PH}$ was more prevalent in hypoxaemic patients with greater impairment in lung function and lower exercise capacity.

\section{Acknowledgements}

We thank the Cardiology Division of the Federal University of São Paulo (São Paulo, Brazil) for their collaboration during this study.

\section{References}

1 Hurdman J, Condliffe R, Elliot CA, et al. ASPIRE registry: Assessing the Spectrum of Pulmonary hypertension Identified at a REferral centre. Eur Respir J 2012; 39: 945-955.

2 Galiè N, Hoeper MM, Humbert M, et al. Guidelines for the diagnosis and treatment of pulmonary hypertension: the task force for the diagnosis and treatment of pulmonary hypertension of the European Society of Cardiology (ESC) and the European Respiratory Society (ERS), endorsed by the International Society of Heart and Lung Transplantation (ISHLT). Eur Heart J 2009; 30: 2493-2537.

3 Lettieri CJ, Nathan SD, Barnett SD, et al. Prevalence and outcomes of pulmonary arterial hypertension in advanced idiopathic pulmonary fibrosis. Chest 2006; 129: 746-752.

4 Shorr AF, Helman DL, Davies DB, et al. Pulmonary hypertension in advanced sarcoidosis: epidemiology and clinical characteristics. Eur Respir J 2005; 25: 783-788.

5 Kimura M, Taniguchi $\mathrm{H}$, Kondoh $\mathrm{Y}$, et al. Pulmonary hypertension as a prognostic indicator at the initial evaluation in idiopathic pulmonary fibrosis. Respiration 2013; 85: 456-463.

6 Hervier B, Meyer A, Dieval C, et al. Pulmonary hypertension in antisynthetase syndrome: prevalence, aetiology and survival. Eur Respir J 2013; 42: 1271-1282.

7 Savale L, Bertoletti L, Cottin V. Should we screen for pulmonary hypertension at the initial evaluation of idiopathic pulmonary fibrosis? Respiration 2013; 85: 452-455.

8 Fisher MR, Forfia PR, Chamera E, et al. Accuracy of Doppler echocardiography in the hemodynamic assessment of pulmonary hypertension. Am J Respir Crit Care Med 2009; 179: 615-621.

9 Rich JD, Shah SJ, Swamy RS, et al. Inaccuracy of Doppler echocardiographic estimates of pulmonary artery pressures in patients with pulmonary hypertension: implications for clinical practice. Chest 2011; 139: 988-993. 
Arcasoy SM, Christie JD, Ferrari VA, et al. Echocardiographic assessment of pulmonary hypertension in patients with advanced lung disease. Am J Respir Crit Care Med 2003; 167: 735-740.

11 Nathan SD, Shlobin OA, Barnett SD, et al. Right ventricular systolic pressure by echocardiography as a predictor of pulmonary hypertension in idiopathic pulmonary fibrosis. Respir Med 2008; 102: 1305-1310.

12 Lima MS, Coletta ENAM, Ferreira RG, et al. Subacute and chronic hypersensitivity pneumonitis: histopathological patterns and survival. Respir Med 2009; 103: 508-515.

13 Costabel U, Bonella F, Guzman J. Chronic hypersensitivity pneumonitis. Clin Chest Med 2012; 33: 151-163.

14 Selman M, Pardo A, King TE Jr. Hypersensitivity pneumonitis: insights in diagnosis and pathobiology. Am J Respir Crit Care Med 2012; 186: 314-324.

15 Lupi-Herrera E, Sandoval J, Bialostozky D, et al. Extrinsic allergic alveolitis caused by pigeon breeding at a high altitude (2,240 meters). Hemodynamic behavior of pulmonary circulation. Am Rev Respir Dis 1981; 124: 602-607.

16 Costabel U, Matthys H, Ruehle KH. Pulmonary arterial hypertension in extrinsic allergic alveolitis (EAA). Am Rev Respir Dis 1982; 126: 184.

17 Koschel DS, Cardoso C, Wiedemann B, et al. Pulmonary hypertension in chronic hypersensitivity pneumonitis. Lung 2012; 190: 295-302.

18 Mahler DA, Weinberg DH, Wells CK, et al. The measurement of dyspnea. Contents, interobserver agreement, and physiologic correlates of two new clinical indexes. Chest 1984; 85: 751-758.

19 Fink JN, Ortega HG, Reynolds HY, et al. Needs and opportunities for research in hypersensitivity pneumonitis. Am J Respir Crit Care Med 2005; 171: 792-798.

20 Lacasse Y, Selman M, Costabel U, et al. Clinical diagnosis of hypersensitivity pneumonitis. Am J Respir Crit Care Med 2003; 168: 952-958.

21 Silva CIS, Churg A, Müller NL. Hypersensitivity pneumonitis: spectrum of high-resolution CT and pathologic findings. Am J Roentgenol 2007; 188: 334-344.

22 Myers JL. Hypersensitivity pneumonia: the role of lung biopsy in diagnosis and management. Mod Pathol 2012; 25: Suppl. 1, S58-S67.

23 Gottdiener JS, Bednarz J, Devereux R, et al. American Society of Echocardiography recommendations for use of echocardiography in clinical trials. J Am Soc Echocardiogr 2004; 17: 1086-1119.

24 Caminati A, Cassandro R, Harari S. Pulmonary hypertension in chronic interstitial lung diseases. Eur Respir Rev 2013; 22: 292-301

25 Hamada K, Nagai S, Tanaka S, et al. Significance of pulmonary arterial pressure and diffusion capacity of the lung as prognosticator in patients with idiopathic pulmonary fibrosis. Chest 2007; 131: 650-656.

26 Nadrous HF, Pellikka PA, Krowka MJ, et al. Pulmonary hypertension in patients with idiopathic pulmonary fibrosis. Chest 2005; 128: 2393-2399.

27 Farkas L, Gauldie J, Voelkel NF, et al. Pulmonary hypertension and idiopathic pulmonary fibrosis: a tale of angiogenesis, apoptosis, and growth factors. Am J Respir Cell Mol Biol 2011; 45: 1-15.

28 Handa T, Nagai S, Miki S, et al. Incidence of pulmonary hypertension and its clinical relevance in patients with sarcoidosis. Chest 2006; 129: 1246-1252.

29 Corte TJ, Wells AU, Nicholson AG, et al. Pulmonary hypertension in sarcoidosis: a review. Respirology 2011; 16 : 69-77.

30 Nunes H, Humbert M, Capron F, et al. Pulmonary hypertension associated with sarcoidosis: mechanisms, haemodynamics and prognosis. Thorax 2006; 61: 68-74.

31 Bourbonnais JM, Samavati L. Clinical predictors of pulmonary hypertension in sarcoidosis. Eur Respir J 2008; 32: 296-302.

32 Cordova FC, D’Alonzo G. Sarcoidosis-associated pulmonary hypertension. Curr Opin Pulm Med 2013; 19 : $531-537$.

33 El Chami H, Hassoun PM. Immune and inflammatory mechanisms in pulmonary arterial hypertension. Prog Cardiovasc Dis 2012; 55: 218-228.

34 Voelkel NF, Cool CD. Pulmonary vascular involvement in chronic obstructive pulmonary disease. Eur Respir J 2003; 22: Suppl. 46, 28s-32s.

35 Witzenrath M, Ahrens B, Kube SM, et al. Allergic lung inflammation induces pulmonary vascular hyperresponsiveness. Eur Respir J 2006; 28: 370-377.

36 Daley E, Emson C, Guignabert C, et al. Pulmonary arterial remodeling induced by a Th2 immune response. J Exp Med 2008; 205: 361-372.

37 Gläser S, Noga O, Koch B, et al. Impact of pulmonary hypertension on gas exchange and exercise capacity in patients with pulmonary fibrosis. Respir Med 2009; 103: 317-324.

38 Boutou AK, Pitsiou GG, Trigonis I, et al. Exercise capacity in idiopathic pulmonary fibrosis: the effect of pulmonary hypertension. Respirology 2011; 16: 451-458.

39 Gaxiola M, Buendía-Roldán I, Mejía M, et al. Morphologic diversity of chronic pigeon breeder's disease: clinical features and survival. Respir Med 2011; 105: 608-614.

40 Pérez-Padilla R, Salas J, Chapela R, et al. Mortality in Mexican patients with chronic pigeon breeder's lung compared with those with usual interstitial pneumonia. Am Rev Respir Dis 1993; 148: 49-53. 